\title{
Chronic Inflammation in Prostate Biopsy Cores is an Independent Factor that Lowers the Risk of Prostate Cancer Detection and is Inversely Associated with the Number of Positive Cores in Patients Elected to a First Biopsy
}

\author{
Antonio B. Porcaro ${ }^{\mathrm{a}} \quad$ Giovanni Novella $^{\mathrm{a}} \quad$ Daniele Mattevi $^{\mathrm{a}} \quad$ Leonardo Bizzotto $^{\mathrm{a}}$

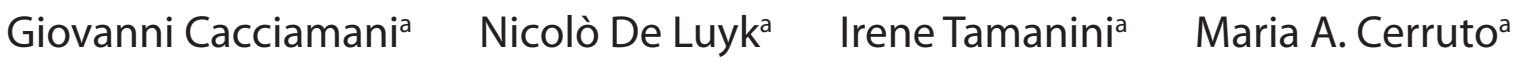 \\ Matteo Brunellib Walter Artibani ${ }^{\mathrm{a}}$ \\ aUrologic Clinic; and bepartment of Pathology, University Hospital, Ospedale Policlinico, Azienda Ospedaliera Universitaria \\ Integrata, Verona, Italy
}

\section{Key Words}

Prostate cancer • Chronic inflammation • Prostate biopsy •

Prostate-specific antigen $\cdot$ Prostate volume

\begin{abstract}
Objectives: To investigate associations of chronic inflammatory infiltrate (CII) with prostate cancer ( $\mathrm{PCa}$ ) risk and the number of positive cores in patients elected to a first set of biopsies. Materials and Methods: Excluding criteria were as follows: active surveillance, prostate specific antigen (PSA) $\geq$ $30 \mathrm{ng} / \mathrm{l}$, re-biopsies, incidental PCa, less than 14 cores, metastases, or 5 -alpha reductase inhibitors. The cohort study was classified as negative (control group) and positive cores between 1 and 2 or $>2$. Results: The cohort included 421 cases who did not meet the exclusion criteria. PCa was detected in 192 cases (45.6\%) of which the number of positive cores was between 1 and 2 in $77(40.1 \%)$ cases. The median PSA was $6.05 \mathrm{ng} / \mathrm{ml}$ (range $0.3-29 \mathrm{ng} / \mathrm{ml}$ ). Linear regression models showed that CII was an independent predictor in-
\end{abstract}

\section{KARGER}

Fax +4161306 1234

E-Mail karger@karger.ch

www.karger.com
(C) 2015 S. Karger AG, Basel

1015-9770/14/0092-0082\$38.00/0

Accessible online at:

www.karger.com/cur versely associated with the risk of PCa. Multinomial logistic regression models showed that $\mathrm{Cll}$ was an independent factor that was inversely associated with PCa risk in cases with positive cores between 1 and $2(O R=0.338 ; p=0.004)$ or more than $2(O R=0.076 ; p<0.0001)$ when compared to the control group. Conclusion: In a cohort of men undergoing the first biopsy set after prostate assessment, the presence of $\mathrm{CIl}$ in the biopsy core was an independent factor inversely associated with PCa risk as well as with the number of positive biopsy cores (tumor extension). Clinically, the detection of $\mathrm{Cll}$ in negative biopsy cores might reduce the risk of $\mathrm{PCa}$ in repeat biopsies as well as the probability of detecting multiple positive cores.

Copyright $\odot 2015$ S. Karger AG, Basel 
Table 1. Classification of prostatitis accordig to National Institutes of Health

\begin{tabular}{|c|c|c|}
\hline Category & Definition & Description \\
\hline I & Acute bacterial prostatitis & $\begin{array}{l}\text { characterized by sudden fever, perineal and suprapubic pain and voiding symptoms. } \\
\text { The urine shows signs of a urinary tract infection. }\end{array}$ \\
\hline III & The CPPS & $\begin{array}{l}\text { characterized by pain and voiding symptoms for more than } 3 \text { months, without de- } \\
\text { tection of bacterial pathogens using standard microbiological methods. The CPPS is } \\
\text { divided into two subcategories: }\end{array}$ \\
\hline IIIb & The noninflammatory CPPS & $\begin{array}{l}\text { characterized by a chronic pelvic pain syndrome without signs of prostatic } \\
\text { inflammation (see category IIIA). }\end{array}$ \\
\hline IV & $\begin{array}{l}\text { Asymptomatic inflammatory } \\
\text { prostatitis }\end{array}$ & $\begin{array}{l}\text { Patients have evidence for prostate inflammation (leukospermia, white blood cells } \\
\text { in expressed prostate secretions, positive cultures or inflammation in tissue biopsies) } \\
\text { without pelvic pain or voiding symptoms. }\end{array}$ \\
\hline
\end{tabular}

CPPS $=$ Chronic pelvic pain syndrome EPS = espressed prostatic secretion.

\section{Introduction}

Inflammation is known to be associated with several cancers such as gastric, colon, esophageal and lung cancers, and hepatocellular carcinoma [1]. Basic science has shown that chronic inflammation plays an important role in human carcinogenesis [1-3]. Indeed, the development and progression of cancer might be related to reactive oxygen and nitrogen species developing in the tissue microenvironment after related damage and regeneration. It has been suggested that exposure to non-steroidal anti-inflammatory drugs (NSAID) reduces the risk of carcinogenesis [4].

In approaching prostate diseases, it is important that consider the concept of zonal anatomy in order to locate and differentiate growth processes [5] which include benign prostate hyperplasia $(\mathrm{BPH})$ and prostate cancer (PCa). In clinical practice, $\mathrm{BPH}$ and $\mathrm{PCa}$ may both be associated with chronic inflammation $[6,7]$ that has been classified in 4 categories by the National Institutes of Health [8]. The last category, that is coded type IV, is detected in prostate biopsy cores of patients who present increased levels of prostate-specific antigen (PSA) with or without an abnormal digital rectal exam (DRE) and have no history of genitourinary tract pain complaints. The 4 categories of National Institutes of Health are presented in Table 1. The presence of chronic inflammatory infiltrate (CII) of the prostate might be related to the pathogenesis and progression of $\mathrm{BPH}$ [6]. Chronic inflammatory infiltrate of the prostate is also associated with $\mathrm{PCa}$, but the nature of the relation, which might be protective or not, is still controversial and unsettled [7]. Indeed, an inverse association between CII and PCa has been reported by previous studies [9-17]. However, the subject has also been approached by other investigators who failed to detect any association [18-20].

In 2 different cohorts of patients, we showed that CII of the prostate is inversely associated with the risk of PCa detection $[9,10]$. The present study investigates the association of CII with the risk of PCa as well as with the number of tumor positive cores in a new cohort of patients elected to a first set of biopsies because of suspected cancer.

\section{Material and Methods}

We retrospectively reviewed the records of 1,260 patients who underwent transrectal ultrasound (TRUS) biopsy at our institution in a period between September 2010 and September 2014.

The study excluded patients who had re-biopsy, were in active surveillance, had levels of PSA $\geq 30 \mathrm{ng} / \mathrm{ml}$, were metastatic, had less than 14 biopsy cores, had a painful rectal exam, had previous prostate surgery for $\mathrm{BPH}$, assumed 5-alpha reductase inhibitors, or showed acute inflammation in the biopsy cores. Patients who were metastatic or showed total PSA levels higher than $30 \mathrm{ng} /$ $\mathrm{ml}$ were excluded because of confounding the aim of the study which focused on evaluating a homogenous cohort undergoing a 


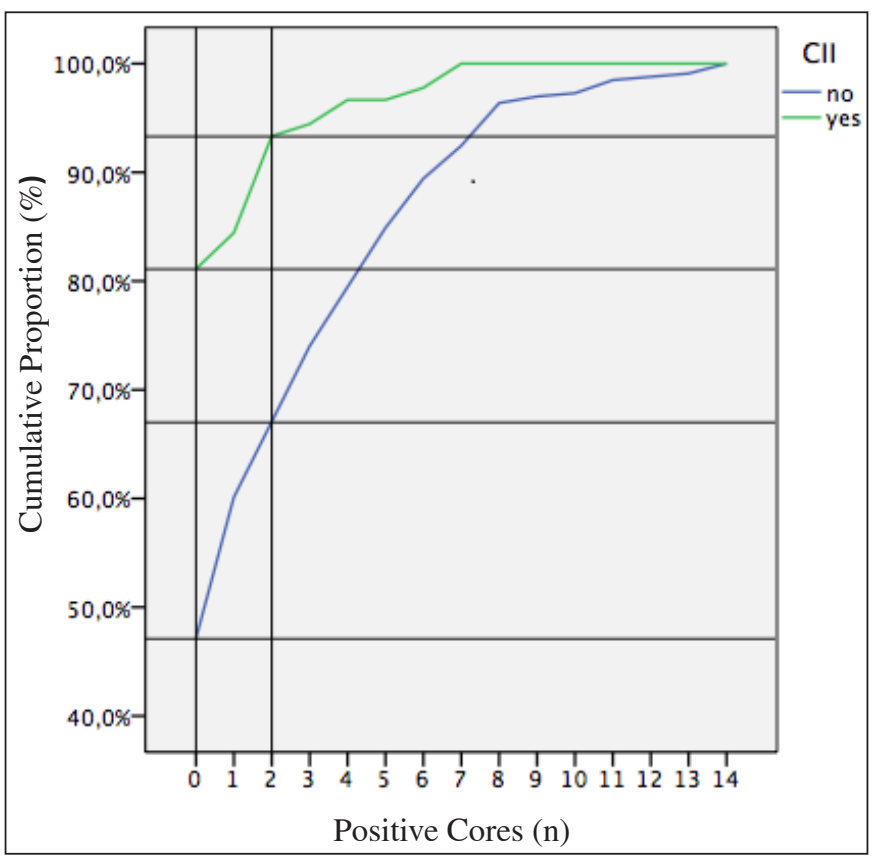

Fig. 1. Cumulative proportion of tumour positive cores as a function of the number of positive cores (range 0-14) in the cohort of patients who are stratified in two groups according to the presence or absence of CII (see results and discussion for details). n, number of positive cores which range between $0(n=0)$ and $14(n=$ 14).

first prostate biopsy set because of suspected cancer. The excluded patients $(\mathrm{n}=839)$ were as follows: (i) PSA $>30 \mathrm{ng} / \mathrm{ml}, \mathrm{n}=37$ (3.7\%), (ii) $\mathrm{M}+, \mathrm{n}=13(1.03 \%$ ), (iii) number of biopsy cores less than $14, \mathrm{n}=40(3.17 \%)$, (iv) painful rectal exam, $\mathrm{n}=25(1.98 \%)$, (v) prostate surgery for $\mathrm{BPH}, \mathrm{n}=50(3.96 \%)$, (vi) medicated by 5-alpha reductase inhibitors, $\mathrm{n}=125$ (9.92\%), (vii) acute inflammation, $\mathrm{n}=15(1.9 \%)$, (viii) active surveillance, $\mathrm{n}=91(7.22 \%)$, and (ix) re-biopsy, $\mathrm{n}=483(38.3 \%)$.

The main indications were as follows: 1) increased levels of PSA, 2) abnormal DRE, 3) increased PSA with abnormal DRE, and 4) abnormal ultrasound imaging of the prostate with normal PSA and DRE. Abnormal DRE findings included a diffusely hard prostate, discrete firm area, irregular contours, or prominent lobe asymmetry. Family history of PCa and smoking was also investigated.

Collection and use of patient data, who signed informed consent, had Institutional Board Review approval. All data were prospectively collected and retrospectively analyzed. Age (years) and body mass index (BMI, $\mathrm{kg} / \mathrm{m}^{2}$ ) were calculated in each patient. PSA was measured by an immuno-radiometric test (normal range: $2-4 \mathrm{ng} / \mathrm{ml}$ ). The volume of the prostate was measured by TRUS before performing biopsies and was computed by a 3-dimensional formula that was transformed into volume $(\mathrm{ml})$. The density of PSA (PSAD) was also computed.

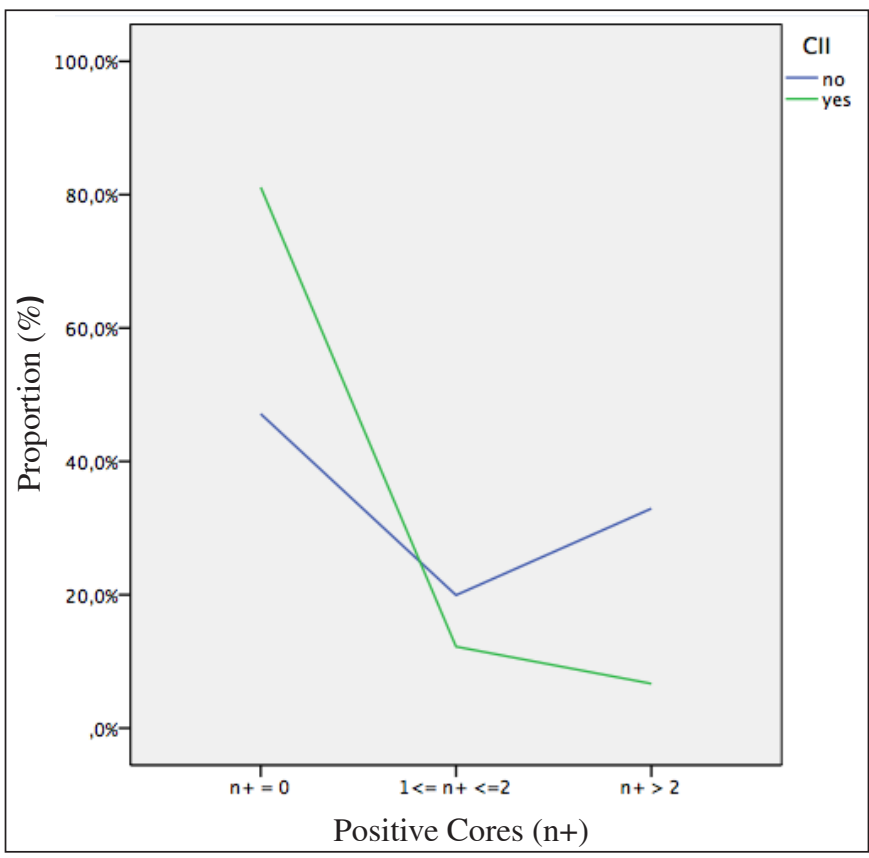

Fig. 2. Proportion of tumour positive cores according to the presence or absence of CII in the biopsy core specimen in the cohort of patients who are stratified into three groups that include patients whose number of positive cores are zero ( $\mathrm{n}+=$ zero; control group), between 1-2 or more than 2 (see results and discussion for details). $n+$, number of positive biopsy cores; $n+=0$, negative cores; $1 \leq n+\leq 2$, positive core between 1 and $2 ; n+>2$, positive cores more than 2 .

In each biopsy core, a dedicated pathologist systematically assessed the following issues: (i) length, (ii) detection and grade of PCa according to the Gleason Score system, (iii) length of biopsy core involved by $\mathrm{PCa}$, (iv) prostatic intraepithelial neoplasia (PIN), (v) CII, (vi) glandular atrophy, and (vii) atypical small acinar cell proliferation (ASAP). Chronic inflammation criteria included the following findings: (i) inflammatory cell infiltrate within the stroma of the prostate;,(ii) inflammatory cell infiltrate predominantly composed of lymphocytes with admixed plasma cells, and (iii) periglandular distribution of the cell infiltrate. Criteria excluding chronic inflammation were: (i) sheets of neutrophils around and within the glands and (ii) aspects of granulomatous prostatitis. The inflammation was not graded according to the severity. However, in each biopsy core specimen, aggregates and nests of inflammatory cells were characterized by mild (10-15 cells) or moderate (> 15 cells) inflammation which was noticeable at low magnification. Severe inflammation showed extensive sheets of inflammatory cells and was detectable at any magnification.

In the study design, the measurement of cancer and CII were independent to each other. Indeed, the presence of cancer or inflammation precluded the diagnosis of the other. The percentage of positive cores was computed as a function of the number of positive cores which ranged between 0 (cores without cancer) and 
Table 2a. Clinical and pathological characteristics of the study cohort $(\mathrm{N}=421)$

\begin{tabular}{lll}
\hline Continuous & Median & Range \\
\hline Age (years) & 66 & $40-90$ \\
BMI & 26.1 & $18.3-42.4$ \\
PSA (ng/ml) & 6.05 & $0.3-29$ \\
PV $(\mathrm{ml})$ & 36.8 & $73-114.8$ \\
PSAD $(\mathrm{ng} / \mathrm{ml})$ & 0.16 & $0.01-1.2$ \\
$\mathrm{~N}(\mathrm{n})$ & 14 & $14-15$ \\
$\mathrm{~L}(\mathrm{~mm})$ & 19.5 & $10-36$ \\
$\mathrm{~N}+(\mathrm{n})$ & 3.0 & $1-14$
\end{tabular}

$\mathrm{PV}=$ Prostate volume; $\mathrm{N}=$ number of biopsy cores; $\mathrm{L}=$ length of cores.

Table 2b. Clinical and pathological characteristics of the study cohort $(\mathrm{N}=421)$

\begin{tabular}{|c|c|c|}
\hline Categorical & $\mathrm{n}$ & $\%$ \\
\hline \multicolumn{3}{|l|}{ FAM } \\
\hline no & 357 & 84.8 \\
\hline yes & 64 & 15.2 \\
\hline \multicolumn{3}{|l|}{ SMK } \\
\hline no & 218 & 51.8 \\
\hline yes & 203 & 48.2 \\
\hline \multicolumn{3}{|l|}{ DRE } \\
\hline normal & 338 & 80.3 \\
\hline anormal & 83 & 19.7 \\
\hline \multicolumn{3}{|l|}{$\mathrm{PCa}$} \\
\hline no & 229 & 54.4 \\
\hline yes & 192 & 45.6 \\
\hline \multicolumn{3}{|l|}{ CII } \\
\hline no & 331 & 78.6 \\
\hline yes & 90 & 21.4 \\
\hline \multicolumn{3}{|l|}{ GA } \\
\hline no & 391 & 92.9 \\
\hline yes & 30 & 7.1 \\
\hline \multicolumn{3}{|l|}{ ASAP } \\
\hline no & 367 & 87.2 \\
\hline yes & 54 & 12.8 \\
\hline \multicolumn{3}{|l|}{ PIN } \\
\hline no & 403 & 95.7 \\
\hline yes & 18 & 4.3 \\
\hline \multicolumn{3}{|l|}{ bGS } \\
\hline 6 & 107 & 55.7 \\
\hline 7 & 69 & 35.9 \\
\hline 8 & 10 & 5.2 \\
\hline 9 & 6 & 3.1 \\
\hline \multicolumn{3}{|l|}{ bGP1 } \\
\hline 3 & 157 & 81.8 \\
\hline 4 & 34 & 17.7 \\
\hline 5 & 1 & 0.5 \\
\hline \multicolumn{3}{|l|}{ bGP2 } \\
\hline 3 & 128 & 66.7 \\
\hline 4 & 57 & 29.7 \\
\hline 5 & 7 & 3.6 \\
\hline \multicolumn{3}{|l|}{$\mathrm{N}+$} \\
\hline $1-2$ & 77 & 40.1 \\
\hline$>2$ & 115 & 59.9 \\
\hline
\end{tabular}

FAM = Family history of PCA; SMK = smoking; GA = glandular atrophy ; bGS = biopsy Gleason score; bGP = biopsy Gleason pattern.

Chronic Inflammation Lowers the Risk of Prostate Cancer in Biopsy Cores

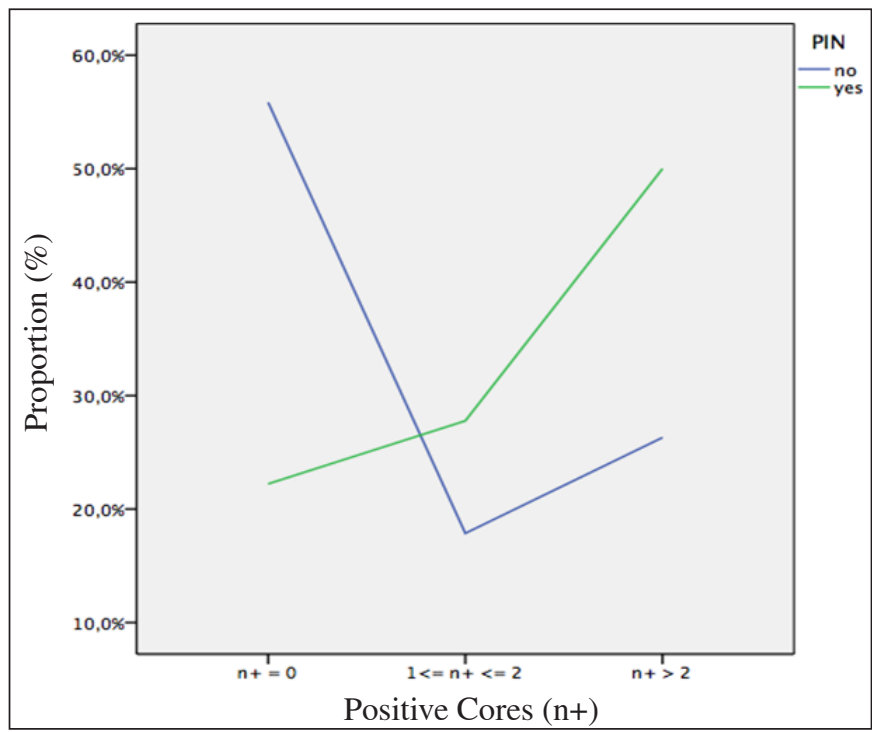

Fig. 3. Proportion of positive cores according to the presence or absence of PIN in the biopsy core in the cohort of patients who are stratified into 3 groups that include cases whose number of positive cores are zero ( $n+=0$; control group), between $1-2$ or more than 2 (see results and discussion for details). $\mathrm{n}+=0$, negative cores; $1 \leq n+\leq 2$, positive core between 1 and 2 ; $n+>2$, positive cores more than 2 .

14 (fig. 1). The percentage of positive cores were assessed in the cohort of patients who were stratified by the number of positive cores (zero, between 1 and 2, and more than 2) and the presence or absence of CII (fig. 2). The percentage of positive cores was computed in the cohort of patients who were stratified by the number of positive cores (zero, between 1 and 2, and more than 2) and the presence or absence of PIN (fig. 3).

Data on continuous variables are reported as medians with their respective ranges, and differences between groups were analyzed with the Kruskal-Wallis test. The $\mathrm{X}^{2}$ statistic was computed to test categorical variables. Data on categorical variables are presented as proportions, and differences between groups were analyzed with Pearson's chi-squared test or Fisher exact test as appropriate. To generate simple linear regression models of covariates associated with the number of positive cores $(\mathrm{N}+)$, all continuous variables were entered as continuous variables unless otherwise stated. Only variables that were significant in univariate models were included in the multivariable analysis. Where significant colinearity existed between independent variables, the one with the most predictive power was given preference in the multivariate model. Multivariate models were generated using a simple stepwise model. To generate simple and multivariate multinomial logistic regression models of predictors associated with the number of positive cores between 1 and $2(1 \leq \mathrm{N}+\leq 2)$ or more than $2(\mathrm{~N}+$ $>2)$ both were compared with the cancer negative group $(\mathrm{N}+=0)$, and all continuous variables were entered as continuous variables unless otherwise stated.

All tests were two-sided with $\mathrm{p}<0.05$ considered to indicate statistical significance. 
Table 3a. Factors associated with the number of positive-cores $(\mathrm{N}+$, range $0-14)$ as determined by linear regression models: Univariate Model

\begin{tabular}{|c|c|c|c|c|c|}
\hline \multirow[t]{2}{*}{ Covariates } & \multirow[t]{2}{*}{ B } & \multirow[t]{2}{*}{$\mathrm{SD}$} & \multicolumn{2}{|c|}{$95 \% \mathrm{CI}$ of $\mathrm{B}$} & \multirow[t]{2}{*}{$\mathrm{p}$} \\
\hline & & & Lower & Upper & \\
\hline Age & 0.057 & 0.017 & 0.024 & 0.090 & 0.01 \\
\hline PSA & 0.177 & 0.035 & 0.109 & 0.246 & $<0.0001$ \\
\hline PV & -0.049 & 0.007 & -0.062 & -0.036 & $<0.0001$ \\
\hline PSAD & 9,025 & 0.823 & 7,408 & 10,643 & $<0.0001$ \\
\hline CII & -1.629 & 0.328 & -2.274 & -0.984 & $<0.0001$ \\
\hline GA & -1.16 & 0.535 & -2.168 & -0.068 & 0.038 \\
\hline ASAP & -1.044 & 0.411 & -1.852 & -0.237 & 0.011 \\
\hline PIN & 0.519 & 0.684 & 0.825 & 1,863 & 0.448 \\
\hline
\end{tabular}

Table 3b. Factors associated with the number of positive-cores (N+, range 0-14) as determined by linear regression models: Multivariate Model

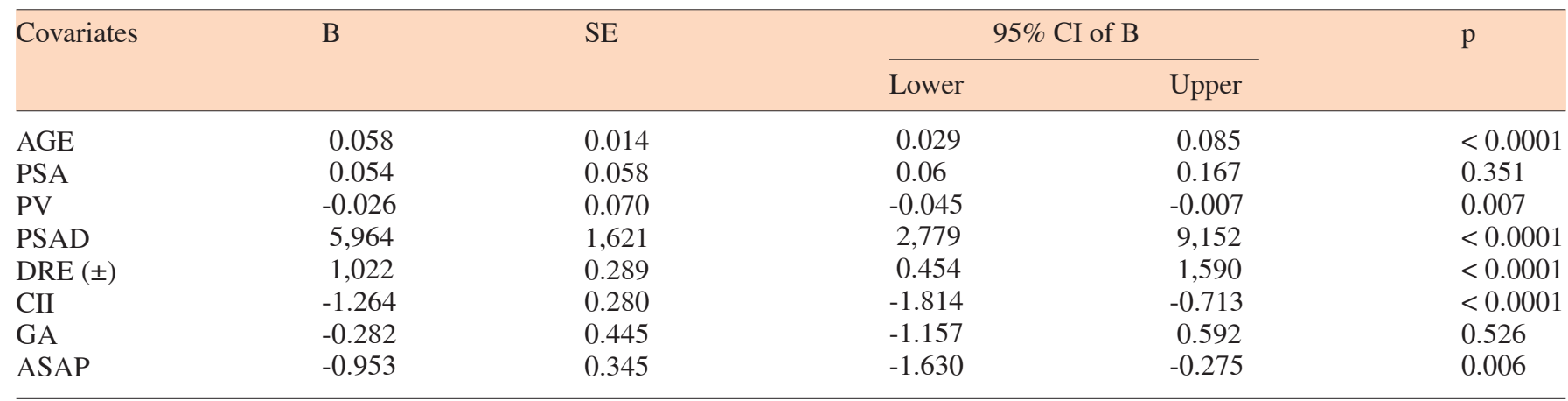

$\mathrm{B}=$ Regression coefficient $\mathrm{SD}=$ standard deviation; $\mathrm{SE}=$ standard error.

\section{Results}

The present analysis relates to 421 patients who did not meet our exclusion criteria. The main indications to perform a first set of prostate biopsies were as follows: (i) increased PSA plasma levels (74.8\%), (ii) increased PSA plasma levels and abnormal DRE (15.2\%), abnormal imaging of the prostate with normal PSA and DRE (5.7\%), or abnormal DRE with normal PSA (4.3\%). Clinical and pathologic characteristics of the study cohort are reported in Table 2 which shows that abnormal DRE was present in $19.7 \%$ of cases, the median plasma levels of PSA was $6.05 \mathrm{ng} / \mathrm{ml}$, the median age was 66 years, and the median volume of the prostate was 36.8 ml. Prostate cancer was detected in 192 cases $(45.6 \%$ ) and CII was present in 90 patients $(21.4 \%)$. The median number of cores was 14 (range 14-15) and the median length of each core was $19.5 \mathrm{~mm}$ (range 10-36 mm). The median number of positive cores was 3 (range 1-14). The number of positive cores was at least 1 or 2 in 77 patients $(40.1 \%)$ and more than 2 in 115 patients $(59.9 \%)$.

Table 3 shows the factors associated with the number of positive cores $(\mathrm{N}+$, range $0-14)$ as determined by linear regression models. In the multivariate model, the covariates positively associated with $\mathrm{N}+$ were age $(\mathrm{b}=$ $0.05 ; \mathrm{p}<0.0001)$, PSAD $(\mathrm{b}=5.96 ; \mathrm{p}<0.0001)$, and abnormal DRE $(b=1.022 ; p<0.0001)$. Negative predictors of $\mathrm{N}+$ included volume of the prostate $(\mathrm{b}=-0.026 ; \mathrm{p}=$ $0.007)$, CII ( $b=-1.26 ; p<0.0001)$, and ASAP $(b=-0.95$; $\mathrm{p}<0.006)$. 
Table 4. Clinical and pathological factors of patients with a number of positive cores between 1-2 or $>2$ compared with the biopsy negative (control) group

\begin{tabular}{|c|c|c|c|c|c|}
\hline \multirow[t]{2}{*}{ Variables } & \multirow{2}{*}{$\begin{array}{l}\text { Population } \\
(\mathrm{n}=421)\end{array}$} & \multicolumn{3}{|c|}{$\mathrm{N}+$} & \multirow[t]{2}{*}{$\mathrm{p}$} \\
\hline & & $0(n=229)$ & $1-2(n=77)$ & $>2(\mathrm{n}=115)$ & \\
\hline \multicolumn{6}{|c|}{ Continous, median (range) } \\
\hline Age (years) & $66.0(40-90)$ & $65(44-90)$ & $67(45-89)$ & $70(40-83)$ & $<0.0001$ \\
\hline BMI $\left(\mathrm{kg} / \mathrm{m}^{2}\right)$ & $26.1(18.3-42.6)$ & $26.1(18.3-42.6)$ & $26(20.3-35.9)$ & $26.5(19.6-39.1)$ & 0.668 \\
\hline PSA (ng/mL) & $6(0.3-29.0)$ & $6(0.3-23.2)$ & $5.8(1.2-29)$ & $6.2(0.8-27.0)$ & 0.052 \\
\hline $\mathrm{PV}(\mathrm{mL})$ & $36.8(7.3-114.8)$ & $43.3(7.3-114.8)$ & $34.6(12.2-99.3)$ & $28.4(12.5-77.7)$ & $<0.0001$ \\
\hline PSAD (ng/mL) & $0.16(0.01-1.2)$ & $0.13(0.01-1.0)$ & $0.17(0.03-0.82)$ & $0.22(0.2-1.2)$ & $<0.0001$ \\
\hline \multicolumn{6}{|l|}{ Categorical, n (\%) } \\
\hline FAM & & & & & 0.069 \\
\hline No & $357(84.8)$ & $199(47.3)$ & $68(16.2)$ & $90(21.4)$ & \\
\hline Yes & $64(15.2)$ & $30(7.1)$ & $9(2.1)$ & $25(5.9)$ & \\
\hline SMK & & & & & 0.652 \\
\hline No & $218(51.8)$ & $123(29.2)$ & $37(8.8)$ & $58(13.8)$ & \\
\hline Yes & $203(48.2)$ & $106(25.2)$ & $40(9.5)$ & $57(13.5)$ & \\
\hline $\operatorname{DRE}( \pm)$ & & & & & 0.002 \\
\hline No & $338(80.3)$ & $197(46.8)$ & $60(14.3)$ & $81(19.2)$ & \\
\hline Yes & $83(19.7)$ & $32(7.6)$ & $17(4)$ & $34(8.1)$ & \\
\hline CII & & & & & $<0.0001$ \\
\hline No & 331 (78.6) & $156(37.1)$ & $66(15.7)$ & 109 (25.9) & \\
\hline
\end{tabular}

Table 4 shows the clinical and pathological factors of patients with the number of positive cores between 1 and 2 or $>2$ compared with the biopsy negative group. Patients who had more than 2 positive cores showed significant differences related to age (older), PSAD (higher), volume of the prostate (smaller), abnormal DRE (higher rates), CII (lower rates), glandular atrophy (lower rates), ASAP (lower rates), and PIN (higher rates) than cases who were negative or had 1-2 positive cores. Table 5 shows the covariates associated with the number of positive cores between 1 and 2 or $>2$ compared with biopsy negative cases by multinomial logistic regression models. In the multivariate models, patients with 1-2 positive cores showed significant differences related to age $(\mathrm{p}=$ $0.011)$, volume of the prostate $(\mathrm{p}=0.019)$, PSAD $(\mathrm{p}=$ $0.005)$, and CII $(\mathrm{p}=0.004)$; and patients with $>2$ positive cores showed significant difference related to age $(\mathrm{p}<$ $0.0001)$, volume of the prostate $(\mathrm{p}<0.0001)$, PSAD ( $\mathrm{p}$ $<0.0001)$, abnormal DRE ( $\mathrm{p}=0.010)$, CII $(\mathrm{p}<0.0001)$, and PIN $(p=0.030)$. Finally, differences between groups with 1-2 positive cores and $>2$ positive cores included abnormal DRE and PIN.

Figure 1 shows the cumulative proportion of positive cores as a function of $\mathrm{N}+$ (range 0-14), stratified into groups with or without CII. Patients who had CII in the biopsy core showed higher negative proportion rates $(81.1 \%)$ than those without $(47.1 \%)$, Moreover, cases with 1-2 positive cores were proportionally lower (18.9\%) in the CII subgroup than those without CII (42.8\%). Figure 2 depicts the cumulative proportion of positive cores in the patient population stratified into 3 groups by the number of positive cores. The rates related to 1-2 or more than 2 positive cores were significantly lower in the CII group than in the other without CII. Moreover, the number of cases with $>2$ positive cores decreased in the CII group and increased in the cluster without CII. Figure 3 outlines the independent and positive association of PIN with the number of positive cores including 1-2 or $>2$. As shown, the proportion of positive cores was increasingly higher in PIN patients than cases without PIN.

The patient study design is summarized by the flow chart image depicted in fig. 4.

\section{Discussion}

In North America and Europe, PCa and CII both show a high prevalence which suggests causality between the two diseases [21]. There is increasing evidence that inflammation might also play a non-negative role. Indeed, in the prostate microenvironment, it has been shown that 
Table 5. Covariates associated with a number of positive cores between 1-2 or $>2$ compared to negative cases by multinomial logistic regression models

\begin{tabular}{|c|c|c|c|c|c|c|c|c|}
\hline \multirow[t]{2}{*}{ Covariates } & \multicolumn{4}{|c|}{$1 \leq \mathrm{N}+<2$ vs. negative group $(\mathrm{N}+=0)$} & \multicolumn{4}{|c|}{$\mathrm{N}+>2$ vs. negative group $(\mathrm{N}+=0)$} \\
\hline & OR & $\begin{array}{c}95 \% \text { CI of OR } \\
\text { Lower }\end{array}$ & $\begin{array}{c}95 \% \text { CI of OR } \\
\text { Upper }\end{array}$ & $\mathrm{p}$ & OR & $\begin{array}{c}95 \% \text { CI of OR } \\
\text { Lower }\end{array}$ & $\begin{array}{l}95 \% \text { CI of OR } \\
\text { Upper }\end{array}$ & $\mathrm{p}$ \\
\hline \multicolumn{9}{|c|}{ Univariate Model } \\
\hline PSA & 1.055 & 0.098 & 1.184 & 0.155 & 1.108 & 1.043 & 1.177 & 0.001 \\
\hline PV & 0.971 & 0.955 & 0.987 & $<0.0001$ & 0.93 & 0.912 & 0.949 & $<0.0001$ \\
\hline PSAD & 567.714 & 35,3 & 380.418 & $<0.0001$ & 13710 & 1006.2 & 186791.7 & $<0.0001$ \\
\hline $\mathrm{CII}$ & 0.356 & 0.178 & 0.714 & 0.004 & 0.118 & 0.049 & 0.28 & $<0.0001$ \\
\hline GA & 0.363 & 0.106 & 1.245 & 0.107 & 0.323 & 0.109 & 0.957 & 0.041 \\
\hline ASAP & 1.545 & 0.783 & 3.048 & 0.209 & 0.478 & 0.212 & 1.076 & 0.074 \\
\hline PIN & 3.906 & 1.022 & 14.938 & 0.046 & 4.776 & 1.438 & 15.86 & 0.011 \\
\hline \multicolumn{9}{|c|}{ Multivariate Model } \\
\hline Age & 1.049 & 1.011 & 1.089 & 0.011 & 1.096 & 1.055 & 1.138 & $<0.0001$ \\
\hline GA & 0.412 & 0.111 & 0.111 & 0.185 & 0.481 & 0.132 & 1.752 & 0.267 \\
\hline ASAP & 1.316 & 0.616 & 0.616 & 0.478 & 0.407 & 0.156 & 1.066 & 0.067 \\
\hline PIN & 2.964 & 0.733 & 0.733 & 0.127 & 4.638 & 1.156 & 18.451 & 0.03 \\
\hline
\end{tabular}

CII might be both pro- and anti-tumorigenic which depends on the immune response [21]. It has recently been shown by the Reduction by Dutasteride of Prostate Cancer Events (REDUCE) study that the association between CII and PCa is protective [16, 17]. Indeed, among men undergoing repeat prostate biopsy after an initial negative baseline biopsy, baseline chronic inflammation was found to be independently associated with both a lower risk and lower volume of PCa. However, the REDUCE study has several limitations related to the inclusion criteria that limit the generalization of the results. Indeed, the selection criteria of the study included only men with PSA values between $2.5 \mathrm{ng} / \mathrm{ml}$ and $10 \mathrm{ng} / \mathrm{ml}$. Moreover, it excluded high-grade PIN, ASAP, volume of the prostate $>80 \mathrm{ml}$, or an International Symptom score $>25$ or $\geq 20$.

The protective association between $\mathrm{CII}$ and $\mathrm{PCa}$ was confirmed by the present study in which CII was detected in $21.4 \%$ of cases and was an independent predictor inversely associated with the number of positive cores. As shown by fig. 1 and 2, the CII group showed higher negative $\mathrm{PCa}$ rates $(81.1 \%)$ and lower PCa detection rates in the subgroups with the number of positive cores between 1 and 2 or more than 2 . As shown by multinomial logistic regression models, the negative association of CII with
$\mathrm{PCa}$ was stronger than the volume of the prostate $(\mathrm{OR}=$ $0.977 ; \mathrm{p}=0.019)$ in both groups including $\mathrm{N}+$ between 1 and $2(\mathrm{OR}=0.338 ; \mathrm{p}=0.004)$ and $\mathrm{N}+>2(\mathrm{OR}=0.076$; $\mathrm{p}<0.0001$ ) when compared to the control (biopsy negative) group.

Our study confirms the protective role of CII in the prostate microenvironment. Although the present investigation shows results which are similar to those of the REDUCE trial, the design of our study differs from the REDUCE trial. Indeed, while the REDUCE study evaluated the association of inflammation in a negative biopsy for cancer with the subsequent risk of prostate cancer detection, our investigation evaluated the association of inflammation and cancer detection in the same biopsy set.

Our study shows results that correlate with those of the REDUCE trial because it confirms the negative association of CII with the risk of PCa detection as well as with the number of positive cores that relate to tumor extension or volume. Moreover, our study allows the generalization of the results since we included a large set of cases which were excluded by the design of the REDUCE trial. The present study shows that, in a cohort of patients elected to first set of prostate biopsies because of suspected cancer, the proportion of $\mathrm{PCa}$ cases with the number of positive cores between 1 and 2 was $40.1 \%$ 


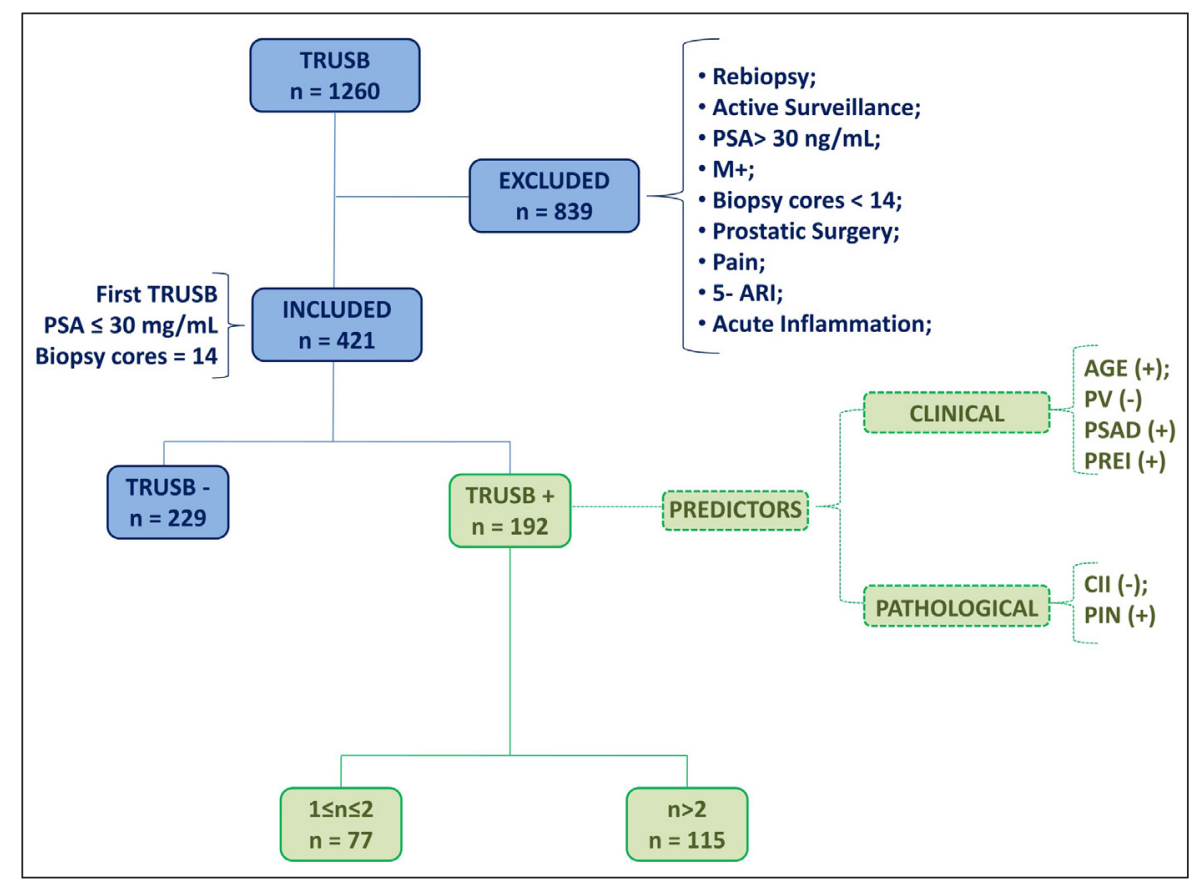

Fig. 4. Flowchart image of the study design.

with a median PSA of $5.8 \mathrm{ng} / \mathrm{ml}$ (Table 2 and 4). In the cohort of PCa patients, cases with 1-2 positive cores represent an important subgroup because of drawbacks in clinical practice. Indeed, the number of positive cores between 1 and 2 is the first parameter to evaluate according to a sequence of steps that will lead to select patients who are candidates for active surveillance. This was the reason that in the design of the study, we evaluated this subset of the PCa population by multinomial logistic regression models.

It has been suggested that infiltrates and mediators of chronic inflammation might be involved in PCa carcinogenesis [22-24]. Because of the association of chronic inflammation with oxidative stress which is mediated by the cyclo-oxygenase gene pathway, it has been proposed that aspirin, which is NSAID, might prevent PCa carcinogenesis by inhibiting the cyclo-oxygenase [25-29]. However, these findings are questionable since there are observational studies showing that PCa risk is increased after NSAID exposure [30-32]. Moreover, cancer susceptibility and severity may be associated with functional polymorphisms of inflammatory cytokine genes, and deletion or inhibition of inflammatory cytokines inhibits the development of experimental cancer [1, 24]. Although the presence of inflammatory cells in the pros-

Chronic Inflammation Lowers the Risk of Prostate Cancer in Biopsy Cores tate is well documented, the relationship between CII and PCa development is limited by the absence of characterization of cellular phenotypes of the leukocytes. Indeed, growing tumors can induce recruitment of immune cells into the prostate microenvironment by secreting many inflammatory factors and cytokines in order to attract the immune cells and initiate a reciprocal interaction that promotes disease progression. However, information regarding the precise profile of prostate tumor-infiltrating leukocytes, which include lymphocytes (T- and B-cells), macrophages, mast-cells, immunosuppressive cells, and neutrophils, is extremely limited. In the early steps in carcinogenesis, the cells of the immune system have the potential to be both anti- or pro-tumorigenic, depending on cellular phenotypes, combinations, localization, and the tumor microenvironment [1]. The prostate is considered an immunocompetent organ in which the environment is populated by inflammatory cells that include the innate (monocytes, macrophages, and mast cells) and adaptive (B and $\mathrm{T}$ lymphocytes) section of the immune system that is currently being studied for PCa immunotherapy strategies [24, 33, 34].

Indeed, anticancer vaccines and immunotherapies focus on empowering the immune system to overcome the tumor $[23,31,32]$ by stimulating the immune system 


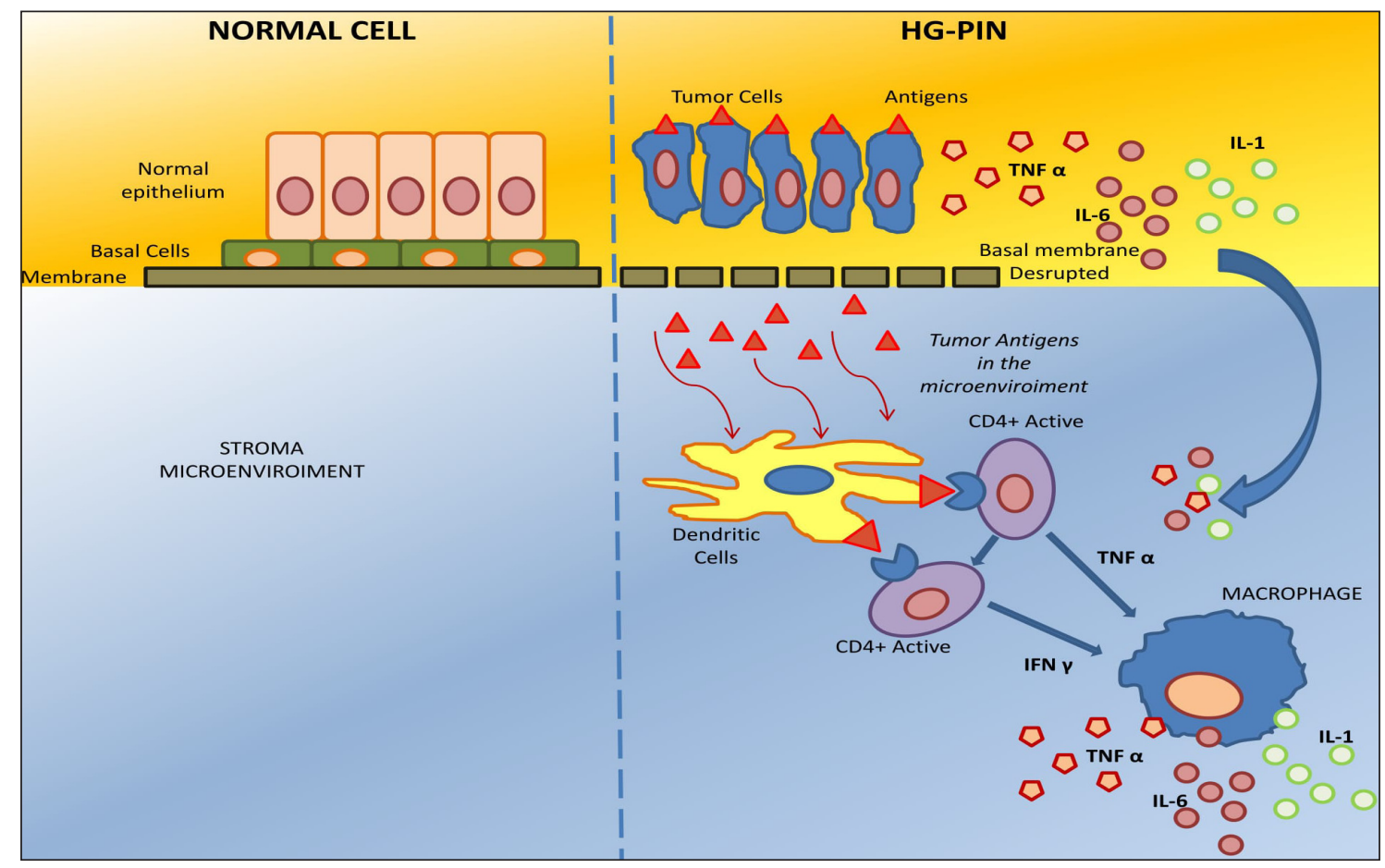

Fig. 5. Diagram showing the theoretic pathway involved by chronic inflammation and cells of the immune system in prostate cancerogenesis (see discussion for details). Legend: TNF, tumour necrosis factor; IL-1, interleukin 1; IL-6, interleukin 6; IFN, interferon gamma.

and activating an appropriate immune-mediated response against malignant cells. The immune system consists of innate and adaptive components. The innate immune system encompasses phagocytic cells, natural killer cells, and cells that release inflammatory mediators. Macrophages and dendritic cells function as antigen presenting cells which serve as a bridge from innate to adaptive immunity. The adaptive arm of the immune system consists of $\mathrm{B}$ cells and $\mathrm{T}$ cells. The $\mathrm{T}$ cells are the most crucial component in mediating antitumor responses induced by cancer vaccines and immunotherapies.

The results of the REDUCE study suggests that CII in the biopsy specimen may lower the risk of subsequent PCa detection on repeat biopsy as well as be associated with less aggressive PCa $[16,17]$. Our study also suggests that CII is an independent factor that lowers both the risk as well as the extension (number of positive cores) of PCa. It is difficult to understand and explain the biology supporting the negative association between CII and with PCa. As a theory, we suggest, as illustrated in fig. 5, a schematic mechanistic diagram showing the potential cellular exchange of signaling pathways to- wards inflammation in PCa. Indeed, in the early stages of PCa carcinogenesis, high grade PIN associates with disruption of the basement membrane which allows cancer cells to induce recruitment of immune cells into the prostate microenvironment by secreting many inflammatory factors and cytokines in order to attract the immune cells and initiate a reciprocal interaction with delivery of tumor antigens. Moreover, macrophages and dendritic cells expose the antigens to both helper (CD4+) and cytotoxic (CD8+) T lymphocytes which trigger a cytotoxic response against the cancer cells structuring the focus of high grade PIN. As a consequence, PCa carcinogenesis progression might be interrupted and the risk of $\mathrm{PCa}$ is reduced because of the activated local immune system.

PSA selection for prostate biopsy may pose a potential bias because its increment also associates with CII [35-37]. In our study, PSA was not an independent covariate associated with the number of positive cores, as assessed by multivariate linear regression models (Table 3). The multinomial logistic regression model also showed that PSA did not have any power in differentiating between biopsy negative cases and patients with 
1-2 positive cores. The present study also confirmed the negative-independent role of the volume of the prostate in detecting PCa [38-39].

The independent role of PSAD in predicting PCa was also confirmed by our investigation [40].

The main differences between PCa cases with 1-2 positive cores and patients with more than 2 cores were the presence of PIN and abnormal DRE as shown by multinomial logistic regression models. Fig. 3 shows the independent and positive association of PIN with PCa. Indeed, the presence of PIN in the biopsy core decreased the probability of a negative biopsy (55.8 vs. $22.2 \%$ ) as well as increased the PCa detection in cases with either $1-2$ cores (17.9 vs. $27.8 \%)$ or $>2$ positive cores (26.3 vs. $50.0 \%)$.

There are limits in our study. First, it was a single centre study, but the sample size was large enough. Second, we measured the volume of the prostate by means of TRUS and not by prostatectomy specimens. However; TRUS is widely used and it is considered an effective technique. Third, the inverse association of chronic inflammation with PCa might be confounded by PSA. In- deed, PSA may be elevated by both inflammation and cancer, and hence, if biopsies are performed in cases with increased PSA, some patients will have cancer and others CII [35-37]. Patients with inflammation may more likely undergo biopsy procedures than men without inflammation because of potential higher PSA levels. As a result, men with CII will automatically be less likely to have cancer and vice versa. Finally, it was not a controlled trial and, although the data were prospectively collected, they were retrospectively analyzed, with the limitations that this engenders.

In summary, we have determined that, in a cohort of men undergoing the first biopsy set after prostate assessment, the presence of CII in the biopsy core is an independent factor that is inversely associated with a lower risk of PCa as well as a lower number of positive biopsy cores indicating tumor extension. Clinically, the detection of CII in negative biopsy cores may reduce the risk of PCa on repeat biopsies as well as the probability of detecting multiple positive cores. The association between $\mathrm{CII}$ and $\mathrm{PCa}$ carcinogenesis remains a controversial issue which needs further clinical and basic research.

\section{References}

1 Balkwill F, Mantovani A: Inflammation and cancer: back to Virchow? Lancet 2001;357: 539-545.

2 Coussens LM, Werb Z: Inflammation and cancer. Nature 2002;420:860-867.

3 Kuraishy A, Karin M, Grivennikov SI: Tumor promotion via injury- and death-induced inflammation. Immunity 2011;35:467-477.

4 Mantovani A, Allavena P, Sica A, Balkwill F: Cancer-related inflammation. Nature 2008; 454:436-444.

5 Selman SH: The McNeal prostate: a review. Urology 2011;78:1224-1228.

6 Gandaglia G, Briganti A, Gontero P, Mondaini N, Novara G, Salonia A, Sciarra A, Montorsi F: The role of chronic inflammation in the pathogenesis and progression of benign prostatic hyperplasia (BPH). BJU Int 2013; 112:432-441.

7 De Nunzio C, Kramer G, Marberger M, Montironi R, Nelson W, Schröder F, Sciarra A, Tubaro A: The controversial relationship between benign prostatic hyperplasia and prostate cancer: the role of inflammation. Eur Urol 2011;60:106-117.
8 Krieger JN, Nyberg L Jr, Nickel JC: NIH consensus definition and classification of prostatitis. JAMA 1999;282:236-237.

9 Porcaro AB, Rubilotta E, Petrozziello A, Ghimenton C, Migliorini F, Zecchini Antoniolli S, La Cola V, Monaco C, Curti P, Cavalleri S, Pianon R, Artibani W: Chronic inflammation of the prostate type IV with respect to risk of prostate cancer. Arch Ital Urol Androl 2014; 86:208-211.

10 Porcaro AB, Novella G, Molinari A, Terrin A, Minja A, De Marco V, Martignoni G, Brunelli M, Cerruto MA, Curti P, Cavalleri S, Artibani W: Prostate volume index and chronic inflammation of the prostate type IV with respect to the risk of prostate cancer. Urol Int 2015;94:270-285.

11 Blumenfeld W, Tucci S, Narayan P: Incidental lymphocytic prostatitis. Selective involvement with non malignant glands. Am J Surg Pathol 1992;16:975-981.
12 Zhang W, Sesterhenn IA, Connelly RR, Mostofi FK, Moul JW: Inflammatory infiltrate (prostatitis) in whole mounted radical prostatectomy specimens from black and white patients is not an etiology for radical difference in prostate specific antigen. J Urol 2000;163:131-136.

13 Gerstenbluth RE, Seftel AD, MacLennan GT, Rao RN, Corty EW, Ferguson K, Resnick MI: Distribution of chronic prostatitis in radical prostatectomy specimens with up-regulation of bcl-2 in areas of inflammation. J Urol 2002;167:2267-2270.

14 Irani J, Goujon JM, Ragni E, Peyrat L, Hubert J, Saint F, Mottet N: High-grade inflammation in prostate as a prognostic factor for biochemical recurrence after radical prostatectomy. Pathologist Multi Center Study Group. Urology 1999;54:467-472.

15 Karakiewicz PI, Benayoun S, Begin LR, Duclos A, Valiquette L, McCormack M, Bénard F, Saad F, Perrotte P: Chronic inflammation is negatively associated with prostate cancer and high-grade prostatic intraepithelial neoplasia on needle biopsy. Int J Clin Pract 2007; 61:425-430. 
16 Moreira DM, Nickel JC, Gerber L, Muller RL, Andriole GL, Castro-Santamaria R, Freedland SJ: Baseline prostate inflammation is associated with a reduced risk of prostate cancer in men undergoing repeat prostate biopsy: results from the REDUCE study. Cancer 2014;120:190-196.

17 Moreira DM, Nickel JC, Andriole GL, Castro-Santamaria R, Freedland SJ: Chronic baseline prostate inflammation is associated with lower tumor volume in men with prostate cancer on repeat biopsy: results from the REDUCE study. Prostate 2015;75:14921498.

18 Roberts RO, Bergstralh EJ, Bass SE, Lieber MM, Jacobsen SJ: Prostatitis as a risk factor for prostate cancer. Epidemiology 2004;15: 93-99.

19 Davidsson S, Fiorentino M, Andren O, Fang F, Mucci LA, Varenhorst E, Fall K, Rider JR: Inflammation, focal atrophic lesions, and prostatic intraepithelial neoplasia with respect to risk of lethal prostate cancer. Cancer Epidemiol Biomarkers Prev 2010;20:22802287.

20 Engelhardt PF, Brustmann H, Seklehner S, Riedl CR: Chronic asymptomatic inflammation of the prostate type IV and carcinoma of the prostate: is there a correlation? Scand J Urol 2013;47:230-235.

21 Sfanos KS, Hempel HA, De Marzo AM: The role of inflammation in prostate cancer. Adv Exp Med Biol 2014;816:153-181.

22 De Marzo AM, Platz EA, Sutcliffe S, Xu J, Grönberg H, Drake CG, Nakai Y, Isaacs WB, Nelson WG: Inflammation in prostate carcinogenesis. Nat Rev Cancer 2007;7:256269.

23 Sfanos KS, De Marzo AM: Prostate cancer and inflammation: the evidence. Histopathology 2012;60:199-215.

24 Strasner A, Karin M: Immune infiltration and prostate cancer. Front Oncol 2015;5:128.
25 Thun MJ, Henley SJ, Patrono C: Nonsteroidal anti-inflammatory drugs as anticancers agents: mechanistic, pharmacologic, and clinical issues. J Natl Cancer Inst 2002;94: 252-266.

26 Jacobs EJ, Rodriguez C, Mondul AM, Connell CJ, Henley SJ, Calle EE, Thun MJ: A large cohort study of aspirin and other nonsteroidal anti-inflammatory drugs and prostate cancer incidence. J Natl Cancer Inst 2005;97:975-980.

27 Pruthi RS, Derksen JE, Moore D: A pilot study of the cyclooxygenase-2 inhibitor celecoxib in recurrent prostate cancer after definitive radiation therapy or radical prostatectomy. BJU Int 2004;93:275-278.

28 Di Silverio F, Sciarra A, Gentile V: Etericoxib and intermittent androgen deprivation therapy in patients with biochemical progression after radical prostatectomy. Urology 2008; 71:947-951.

29 Bardia A, Platz EA, Yegnasubramanian S, De Marzo AM, Nelson WG: Anti-inflammatory drugs, antioxidants, and prostate cancer prevention. Curr Opin Pharmacol 2009;9:419426.

30 Gridley G, McLaughlin JK, Ekbom A, Klareskog L, Adami HO, Hacker DG, Hoover R, Fraumeni JF Jr: Incidence of cancer among patients with rheumatoid arthritis. J Nat Cancer Inst 1993;85:307-311.

31 Langman MJ, Cheng KK, Gilman EA, Lancashire RJ: Effect anti-inflammatory drugs on overall risk of common cancer: case-control study in general practice research database. BMJ 2000;320:1462-1466.

32 Neugut AI, Rosenberg DJ, Ahsan H, Jacobson JS, Wahid N, Hagan M, Rahman MI, Khan ZR, Chen L, Pablos-Mendez A, Shea S: Association between coronary heart disease and cancer of the breast, prostate and colon. Cancer Epidemiol Biomarkers Prev 1998;7: 869-873.
33 Drake CG: Prostate cancer as a model for tumour immunotherapy. Nat Rev Immunol 2010;10:580-593.

34 Hammerstrom AE, Cauley DH, Atkinson BJ, Sharma P: Cancer immunotherapy: sipuleucel-T and beyond. Pharmacotherapy 2011;31:813-828.

35 Hoekx L, Jeuris W, Van Marck E, Wyndaele $\mathrm{JJ}$ : Elevated serum prostate specific antigen (PSA) related to asymptomatic prostatic inflammation. Acta Urol Belg 1998;66:1-2.

36 Sindhwani P, Wilson CM: Prostatis and serum prostate-specific antigen. Curr Urol Rep 2005;6:307-312.

37 Hochreiter WW: The issue of elevated prostate cancer evaluation in men with elevated prostate-specific antigen and chronic prostatitis. Andrologia 2008;40:130-133.

38 Roobol MJ, Schroder FH, Hugosson J, Jones JS, Kattan MW, Klein EA, Hamdy F, Neal D, Donovan J, Parekh DJ, Ankerst D, Bartsch G, Klocker H, Horninger W, Benchikh A, Salama G, Villers A, Freedland SJ, Moreira DM, Vickers AJ, Lilja H, Steyerberg EW: Importance of prostate volume in the European Randomised Study of Screening for Prostate Cancer (ERSPC) risk calculators: results from the prostate biopsy collaborative group. World J Urol 2012;30:149-155.

39 Al-Azab R, Toi A, Lockwood G, Kulkarni GS, Fleshner N: Prostate volume is strongest predictor of cancer diagnosis at transrectal ultrasound-guided prostate biopsy with prostate-specific antigen values between 2.0 and 9.0 ng/mL. Urology 2007;69:103-107.

40 Benson MC, Whang IS, Pantuck A, Ring K, Kaplan SA, Olsson CA, Cooner WH: Prostate specific antigen density: a means of distinguishing benign prostatic hypertrophy and prostate cancer. J Urol 1992;147:815-816. 